\title{
Gendered Paradigms For Understanding Of Common-Pool Resource With Special Reference To Keenjhar Lake, Sindh
}

\author{
Aijaz Ahmed Sohag \\ Department of Community Health \& Sciences \\ Dewan Medical \& Dental College \\ \& \\ Faraz Ahmed Wajidi \\ Officer, National Bank of Pakistan, Karachi
}

\begin{abstract}
Keenjhar Lake, Pakistan is facing a potentially devastating ecological collapse, threatening the livelihood security of local communities. The purpose of this study was to investigate that how a more sustainable management plan can be forged through the integration of the local experiential knowledge and technocratic conservation values. The analysis gives particular emphasis to gender issues, given the unacknowledged but increasing responsibilities of community based organizations on women issues. Semi-structured interviews with local communities, communitybased organizations and government officials were undertaken to assess the various perceptions of resource use at Keenjhar Lake. The findings illustrate that conflicting understandings of ownership have a detrimental impact on the local perception on environment and prevalence of resource for their livelihood. However, there is an opportunity to foster new vistas of understanding which could be helpful in sustainability of management of resources.

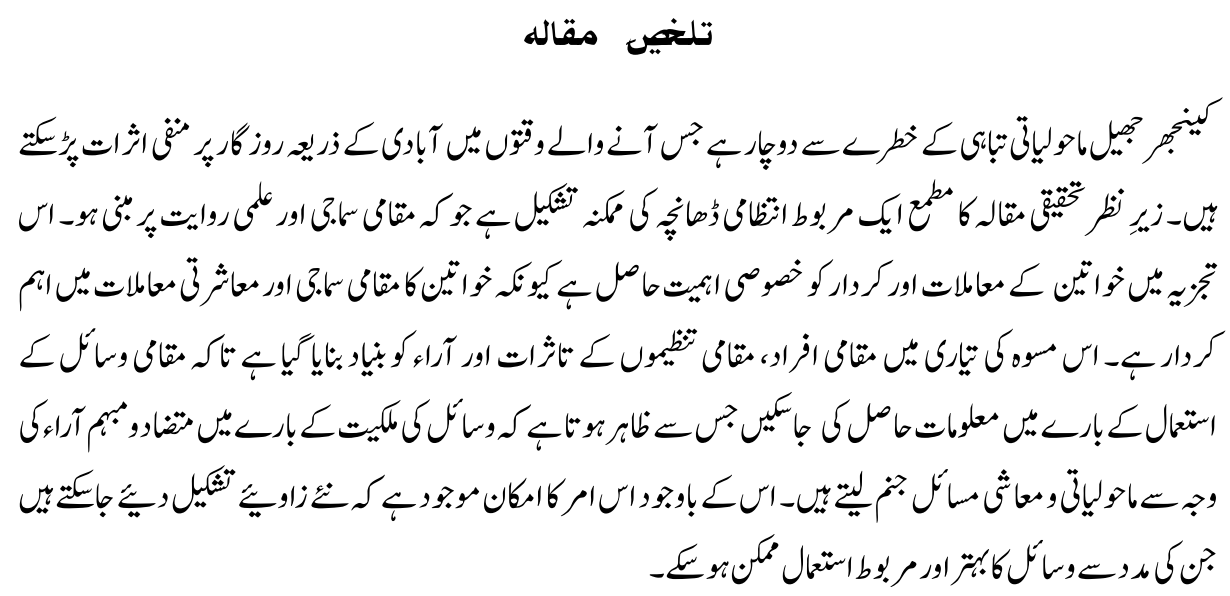

\section{Introduction}

The experienced based knowledge on ecology has developed an increasing importance. The utilization of local knowledge systems is based in the recognition that developing 
nations often lack scientific temporal data or baseline analysis information that can be used to guide restoration and conservation actions. In recent decades, local ecological knowledge has developed an increasing prevalence in the discourse surrounding resource management. The utilization of local knowledge systems is based in the recognition that developing nations often lack scientific temporal data or baseline analysis information that can be used to guide restoration and conservation actions (Ford \& Martinez, 2000). The literature readily recognizes the perceived dichotomy between what is generally referred to as 'western science' versus the commonly titled 'indigenous knowledge'. Further contextualized within this dichotomous relationship are the epistemological variations of the two knowledge systems (Mokuku \& Mokuku, 2004).

The indigenous system is based in contextual and experiential modes, with pragmatic aspects, while the 'western'/Euro-American epistemology is objective, reductionist and mechanistic. In relation to sustainable resource management, often 'western' constructs such as 'eco-tourism' and conservation' (Igoe, 2004) are imported and transposed onto developing nations resource problems. Yet, how appropriate are these constructed solutions for indigenous communities if they are grounded in different epistemological foundations? And, can the acknowledgement of the differences between the two knowledge systems raise the possibility of employing the 'local indigenous knowledge' and the 'western scientific constructs' as complements of one another rather than conflicting systems of resource management?

Based on the above context, this study aims to investigate the potential synthesis of epistemologically differing knowledge systems for the benefit of a declining resource. A single case study will be used to examine this theoretical assumption: Keenjhar Lake and the decline of fishing as a livelihood. Keenjhar Lake is facing a potentially devastating ecological collapse as water quality diminishes, fishing populations decline and industrial pollutants go unmitigated. The livelihood security of the communities surrounding the Lake is subsequently at risk. Consideration of the local ecological knowledge of the surrounding communities as a complementary knowledge system provides an opportunity to engage and utilize their understanding as an integral component of a sustainable resource management plan (Agrawal, A. 1995).

Involvement of stakeholders and the broader governance issues surrounding common pool resources, focusing in on the governance specific and integrating a gendered component of analysis to help develop a more complete understanding of the regional influences on ecological management system and how local knowledge of environmental management situated in scientific perspectives could amalgamate in a meaningful manner to produce a management strategy that is both feasible and sustainable (Ani, M. 1994). The identification of which will help to clarify how various institutional levels connect and interact with each other and the Lake resources. Currently there are six Government 
Departments that perform different functions and have a vested interest in lake resources: Fisheries department, Local Government, Irrigation department, Sindh Tourism Department, Wildlife Department, and Karachi Water and Sewage Board.

In addition to the officially recognized stakeholders, there exist a number of marginalized stakeholders, as well as the lesser-recognized non-human factors involved such as the fish, water, phytoplankton, and wildlife.

\section{Methodology}

Semi-structured interviews with community members surrounding Keenjhar Lake were conducted in ten days duration. Community interviews were often 'group' style interviews, in the presence of village elders.

Additionally interviews were conducted with government departments and with NonGovernmental Organizations (NGOs) working on projects relating to Keenjhar Lake.

\section{Results}

Interviews provided an in-depth look into numerous aspects affecting the livelihood and resources, perceptions of ownership and access, and gendered relations impact on resource management at Keenjhar Lake.

It was interesting to hear the descriptions of responsibilities of women from both the male and female perspectives. Women were often dismissive of the number of responsibilities they had, which included: fetching water, cleaning and mending nets, preparing the meals, watching after the children, washing the clothes, agriculture (when possible), and handiwork in their 'spare' time. However, these domestic responsibilities are often thought of as women's work, and men would not considering doing such things. However the escalating strain on resources causing fishermen to catch fewer and smaller fish has led to an increase of women's responsibilities into male dominated roles. The responsibilities described in interviews include women performing stone mining, fishing and increased agricultural tasks. Women see this added responsibility as a burden and necessity to aid in their family's survival, not necessarily an opportunity to improve their status and equality within the community.

Males often did not speak much about the increasing responsibility on women when asked about the increasing responsibilities of women. The men spoke at length, offering multiple explanations for the increase in ranging from recognition 'Women are working more than men, they are taking care of our homes, children, food, fishing and stone mining, that is our mistake yet when asked why nothing is done to help the women they 
laughed and responded by saying 'Women are not allowed to ask for help as per our culture. The men also became defensive of their lack of increased responsibility, stating that 'We are poor - so we don't have food in our homes, so then the women should work with us, what else they do?'

\section{Discussion}

A study developed basically on interaction with the communities was the emerging role of women responsibilities due to the fisheries decline. Women perform a critical role as the 'daily managers of the living environment'. Yet this realization is often obscured due to the 'imbalance of women's rights and responsibilities as resource managers... and the prevailing "invisibility" of women' (Agarwal, A. 2000). It is therefore necessary to acknowledge and examine the role that gender plays in shaping the patterns of environmental use and management. By recognizing a gendered component within the research aims, it is possible to have a more complete understanding of the ecological management system and framework of the community.

In consideration of the vast cultural and geographical differentiation that exists in gender relations the study examines that women and gender play in the livelihoods and resource management of various regions and resources in Pakistan (Khan, R. 2008). However, as the literature is still a relatively emerging field in Pakistan, it was necessary to draw from some regional sources to enrich the understanding of this complex subject.

The argument advanced here is that women have a situated knowledge of their community and resources that is elemental to understanding effective environmental resource management. Neglect of these considerations can lead to a misjudgment of the success of community institutions, and the lost opportunity of forming successful community management with women's substantial involvement (Mohsin, N. 1999). The establishment of definitional clarifies for terms that are instrumental in providing a brief overview of the common-pool resource management literature.

\section{Common-Pool Resource}

The resource of Keenjhar Lake is often referred to as a common-pool resource, and will be grounded in the theoretical framework of literature surrounding the topic. It is therefore important to have a clear understanding of what is understood as a common pool resource.

(Qureshi, S. 2005) clearly defines the concept as:

"a natural or man-made resource from which it is difficult to exclude or limit users once the resource is provided, and one person's consumption of resource units makes those units unavailable to others" 
The concept of the 'tragedy of the commons' as identified by Garret Hardin represent a theoretical framework surrounding ecological degradation of limited environmental resources by a population. This framework, while based in logical and rational observations of human behavior is grounded assumptions that are open to interpretation (Hardin, 1968). Hardin's argument can be used to support the idea that external authorities can privatize a resource to control local use. This view presupposes that resources users, local peoples, are in a sense trapped in a tragedy of their own making, and centralized management can impose rules and regulations to solve this dilemma (Ostrom, 1999). However, the deleterious effect of this can be seen in multiple case studies where the shift from local to national resulted in weak national oversight replacing invested local management.

Through extensive research and field studies that resources users have the ability to cooperate and overcome resource issues of overuse and degradation. Ostrom establishes that LEK is often grounded in dependence on the responsible management of resources for the livelihood of individuals. Often resources users have an adaptive relationship with the resources they depend on, and adjust their practices, as they perceive to be necessary for the sustainability of the resource.

Resource users generate knowledge based on their actions as the resource itself acts as a feedback mechanism adapting their behavior to the capacity of the local ecosystem (Shaheed, F. and K. Mumtaz 1998). It is therefore important to recognize the role and benefits those dependent upon the resources can offer towards the creation of sustainable resource management plans.

\section{Women and Resources: Emerging Role of Women due to Resource Decline}

Women perform a critical role as the 'daily managers of the living environment'. Yet this realization is often obscured due to the 'imbalance of women's rights and responsibilities as resource managers... and the prevailing "invisibility" of women. It is therefore necessary to acknowledge and examine the role that gender plays in shaping the patterns of environmental use and management. By recognizing a gendered component it is possible to have a more complete understanding of the ecological management system and framework of the community.

In consideration of the vast cultural and geographical differentiation that exists in gender relations. A growing realization examines the role that women and gender play in the knowledge of their community and resources that is elemental to understanding effective environmental resource management. 


\section{Eco-feminism}

The term eco-feminism is believed to have coined by the French writer Francoise d' Eaubonne called upon women to lead an ecological revolution in order to save the planet. It describes movements and philosophies that link feminism with ecology. Combining the words ecology and feminism, eco-feminism embraces the idea that oppression of women or destruction or oppression of nature is closely connected. Some activists of environment call eco-feminism as "third wave of feminist movement".

To date, eco-feminism theory has blossomed, exploring the connections among many issues; racism, environmental degradation, economics, electoral politics, animal liberation, reproductive politics, biotechnology, bioregionalism, spirituality, holistic health practices, sustainable agriculture, and others (King, 1989). Eco-feminism activists have worked in environmental justice movement the Green movement, the anti-toxic movement, the animal liberation movement, and the movement for economic justice.

\section{Status of Women \& Burden of Responsibility}

Over the past decade, there have been a number of changes related to the health and education of women in Pakistan, gradually helping to improve the status of women. Yet, these changes are measured, and a number of women still have little to no access to education and health services. Women still struggle under a gendered barrier that marginalizes both their mobility and interactions.

Women's responsibilities generally include some resource dependant work (this will vary based on the natural resource: collecting wood in forests, making nets in fishing communities) as well as their household duties: sewing, cleaning, 'food processing, cooking, carrying water, and child care.

\section{Local Ecological Knowledge (LEK)}

Experience based knowledge is an emerging concept, currently predominant in the fields of ecological research and resource management. The classification of a knowledge system grounded in experience is a challenging concept due to the complexities based in the diversity of environmental factors, culture, and attributes not normally associated with the empirical nature of science based knowledge. Various references to such knowledge systems are termed as 'Indigenous Knowledge', 'Traditional Ecological Knowledge', 'Rural Peoples' Knowledge' (Kothari,2002) and in certain specified context 'Fish Harvesters' Ecological Knowledge'. 
Each definition is designated by various small distinctions; indigenous knowledge includes the cultural values, beliefs, traditions and worldviews of local peoples as distinguished from 'western science', and is the product of peoples' 'direct experience of the workings of nature and its relationship with the social world'. In general indigenous knowledge will more often refer to a spiritual component inherent in the knowledge system for understanding origin. While traditional ecological knowledge refers more generally to the 'knowledge and insights acquired through extensive observation of an area or species'. For the purposes of this paper, the term local ecological knowledge (LEK) will be used. Reasoning for this is based in the understanding of LEK as an inclusive and encompassing term.

\section{Women and Resources}

A section of research that developed organically from interaction with the communities was the emerging role of women responsibilities due to the fisheries decline. Women perform a critical role as the 'daily managers of the living environment' (Mumtaz, K. 2007). Yet this realization is often obscured due to the 'imbalance of women's rights and responsibilities as resource managers... and the prevailing "invisibility" of women' (Anjum, H. 2002). It is therefore necessary to acknowledge and examine the role that gender plays in shaping the patterns of environmental use and management. By recognizing a gendered component within the research aims, it is possible to have a more complete understanding of the ecological management system and framework of the community (Berkes, F., J. Colding, et al. 2000).

In consideration of the vast cultural and geographical differentiation that exists in gender relations I attempt to situate my gendered analysis into relevant literature directly emerging from and about Pakistan. A growing literature examines the role that women and gender play in the livelihoods and resource management of various regions and resources in Pakistan (Cater, E. 2006). However, as the literature is still a relatively emerging field, it was necessary to draw from some regional sources to enrich the understanding of this complex subject.

The argument advanced here is that women have a situated knowledge of their community and resources that is elemental to understanding effective environmental resource management. Neglect of these considerations can lead to a misjudgment of the success of community institutions, and the lost opportunity of forming successful community management with women's substantial involvement.

\section{Status of Women}

Over the past decade, there have been a number of changes related to the health and education of women in Pakistan, gradually helping to improve the status of women1. Yet, 
these changes are measured, and a number of women still have little to no access to education and health services. Women still struggle under a gendered barrier that marginalizes both their mobility and interactions; for some women, every level of participation in the community is controlled by male relatives.

This restricted access to 'communal' spaces and 'social' activities disenfranchises women from decision making, while this 'stance toward the seclusion of women in many of the households further legitimizes women's lower status and dependency within their household'. This extends to women's (especially rural women's) restricted access to outer world. The primary contributing factor to the 'traditional gender paradigm' (Emeriole, H., T. Munyadzwe, et al. 2001) in Muslim society's highlights:

'This paradigm presumes that a women will marry (early), that the most important contribution to the family and society will be made as a homemaker and mother, that the household will be headed by a man who has a job that will allow him to provide for his family, that the women will depend on the man for support, and that the man's responsibility for supporting and protecting his wife and family Justifies his authority regarding and control over his wife's interactions in the Public sphere'

The gender paradigm is instilled at a young age, reflected in the willingness of parents to first withdraw their female children more readily than males from school due to labor demands in the household. The contributions made to the household in lieu of education are rationalized as preparation for the girl's future role as wives and mothers (Joshi,D. 2009). The gender paradigm not only reinforces a sense of economic and social dependency, but also instigates it through the devaluing of formal education of women. This further hinders the capacity of women to participate in institutionalized and formal resource management.

\section{Women's Social Networks}

Factors such as lack of mobility, lack of representation in local institutions, financial barriers, social norms of gender exclusion and insufficient education often place women in an isolated and vulnerable position. Women therefore have a 'greater need to build up social capital through localized networks, since women's avenues for accumulating economic resources and their physical mobility are typically much more restricted than men's' (Hartwick, E. and Peet,F. 2003). Women utilize and depend on networks to help lighten the burden of responsibilities, as well as exchange information about health and resources.

Women's responsibilities generally include some resource dependent work (this will vary based on the natural resource: collecting wood in forests, making nets in fishing 
communities) as well as their household duties: sewing, cleaning, 'food processing, cooking, carrying water, and child care' (Sanju, 1994). A strong female social network can often have positive impacts at a community level as the social capital helps to

diminish livelihood health risks, especially those involved with mothering and child health (Tunio, S. 2009).

\section{Conclusions}

This study has identified the perceptions of local people to the resource and shifting gender roles. It has also raised several issues to examine how to best operationalize and translate knowledge into sustainable governance structures, as well as enhance the role of women.

This is a necessary endeavor for the creation of a sustainable management plan, without which this resource will continue to deteriorate. It stated that 'To ignore people's knowledge is almost to ensure failure in development'. Echoing this assertion, this study suggests that to ignore local peoples knowledge especially women is to compromise the sustainability of a natural resources.

\section{References}

Agarwal, A. (2000). "Conceptualizing Environmental Collective Action: Why Gender Matters" Cambridge Journal of Economics 24(3): 283-310.

Agrawal, A. (1995). "Dismantling the Divide between Indigenous and Scientific Knowledge" Development and Change 26(3): 413-439.

Ani, M. (1994). An African-Centered Critique of European Cultural Thought and Behavior. Asmara, Africa World Press Inc. 12(2):77-81.

Anjum, H. (2002). "The Cultural Conception and Structural Perpetuation of Female Subordination: An Examination of Gender Relations among Populations of the Chalt-Chaprote Community in the Nagar Valley of Northern Pakistan." Pakistan Development Review 31(4): 621-635.

Berkes, F., J. Colding, et al. (2000). "Rediscovery of Traditional Ecological Knowledge as Adaptive Management." Ecological Applications 10: 1251-1262.

Cater, E. (2006). "Ecotourism as a Western Construct." Journal of Ecotourism 5(2): 23 
Emeriole, H., T. Munyadzwe, et al. (2001). "Rationalization and Science: Instructional Implications of Some Superstitious Beliefs about Natural Phenomena. Journal of Southern African Association of Research in Mathematics and Science Education. 7(5): $65-84$.

Ford, J. and D. Martinez (2000). "Traditional Ecological Knowledge, Ecosystem Science, and Environmental Management." Ecological Applications 10(5): 1249-1250.

Hardin, G. (1968). "The Tragedy of the Commons." Science 162(3859): 1243-48.

Hartwick, E. and Peet,F. (2003). "Neoliberalism and Nature: The Case of the WTO." Annals American Academy of Political and Social Science 590: 188-211.

Igoe, J. (2004). Conservation and Globalization - Indigenous Knowledge for Sustainable Livelihoods and Resources Governance in MMSEA Region. Landscapes of Diversity: Kunming 37(4):14-22.

Joshi,D. (2009). Wetlands in Crisis: Improving Bangladesh's Wetland Ecosystem and Livelihoods of the Poor who Depend on them Integrated Water Resources Management in Practice: Better water management for development. London, Earthscan.41 (1):13-23.

Khan, R. (2008). Indus for All Programme: The Journey Towards a Prosperous Indus Eco Region- Glimpses of 2007-2008. WWF - Pakistan.23: 222-232.

King, Y. (1989). The Ecology of Feminism and Feminism of Ecology. In Healing the Wounds: the Promise of Ecofeminism, ed. Judith Plant Philadelphia: New society Publishers (May): 20-24.

Kothari, B. (2002). "Theoretical Streams in Marginalized Peoples' Knowledge(s): Systems, a Systems and Subaltern Knowledge(s)." Agriculture and Human 19(2): 225-237.

Mohsin, N. (1999). Women at the Edge: Environmental Exploitation and Grassroots Strategies. Karachi, Shirkat Gah.

Mokuku, T. and C. Mokuku (2004). "The Role of Indigenous Knowledge in Biodiversity Conservation in the Lesotho Highlands: Exploring indigenous epistemology." Southern African Journal of Environmental Education 21: 37-49.

Mumtaz, K. (2007). "Gender and Poverty in Pakistan." Development 50(2): 149-154. 
Ostrom, E. (1999). "Coping with Tragedies of the Commons " Annual Review of Political Science 2: 493-535.

Qureshi, S. (2005). Contract System on Inland Fisheries in Sindh and PFF's Struggle. Karachi, Pakistan Fisher folk Forum.

Sanju, M. (1994). "Mountain Ecosystems and Women: Opportunities for Sustainable Development and Conservation." Mountain Research and Development 14(3): 213-228.

Shaheed, F. and K. Mumtaz (1998). Invisible Workers: Piecework Labour amongst Women in Lahore Islamabad, Women's Division Government of Pakistan.22-44.

Tunio, S. (2009). Keenjhar Castes and Tribes. Karachi. "Ecological-Economic Analysis of Wetlands: Integration for Management and Policy." Ecological Economics 35(1): 7-23.

Dr. Aijaz Ahmed Sohag Department of Community Health \& Sciences Dewan Medical \& Dental College, Karachi.

Dr. Faraz Ahmed Wajidi is Senior Officer, National Bank of Pakistan, Karachi. 